\title{
VARIATIONS OF MUSCLE PLANTARIS: ANATOMICAL AND CLINICAL IMPLICATIONS
}

\author{
K. Jayasree1, Ashalatha P. R2, Smitha S. Nair ${ }^{3}$, Jenish Joy ${ }^{4}$ \\ ${ }_{1}^{1}$ Professor \& HOD, Department of Anatomy, Government Medical College, Manjeri. \\ ${ }^{2}$ Associate Professor, Department of Anatomy, Government Medical College, Manjeri. \\ 3 Assistant Professor, Department of Anatomy, Government Medical College, Manjeri. \\ ${ }^{4}$ Lecturer, Department of Anatomy, Government Medical College, Manjeri.
}

\section{ABSTRACT}

\section{AIMS AND OBJECTIVES}

Plantaris is a small fusiform muscle with a long tendon, in the superficial group of flexors of the posterior compartment of leg. Though considered as a vestigial muscle, plantaris is of much importance both from anatomical and clinical point of view, at the same time commanding interest from a phylogenetic perspective also. The muscle is known to present several anatomical variations with respect to its occurrence, origin, course, relations and insertion. It may be absent, unilaterally or bilaterally, though a double occurrence has been rarely reported. The aim of the study is to document the variations in the origin and insertion of plantaris, prevalence of agenesis and the occurrence of accessory plantaris.

\section{STUDY SETTINGS AND DESIGN}

A cadaveric study was conducted on human plantaris muscle in the Department of Anatomy, Government Medical College, Manjeri, Kerala.

\section{MATERIALS AND METHODS}

Fifty lower limbs from twenty five cadavers were dissected and plantaris muscles studied in detail, noting the variations in attachments, and agenesis/accessory plantaris if any. The observations were documented and analysed.

\section{RESULTS AND ANALYSIS}

Of the fifty lower limbs studied, agenesis of plantaris was observed in 4 limbs (8\%) and accessory plantaris or biceps plantaris in 3 limbs (6\%). In the other 43 lower limbs, the pattern of origin belonged to Type 1 in 10 limbs (23.26\%), Type 2 in 7 limbs (16.28\%), Type 3 in 20 limbs (46.51\%) and Type 5 in 6 limbs (13.95\%) and the pattern of insertion belonged to Type 1 in 17 limbs (39.53\%), Type 3 in 6 limbs (13.95\%) and Type 5 in 20 limbs (46.51\%), according to the classification followed in the study.

\section{CONCLUSION}

The anatomical variations of the muscle plantaris and its agenesis/accessory occurrence have significant clinical implications. Considering the relevance of the muscle in the diagnosis of undefined leg pain, use of the tendon in reconstructive surgeries, the importance of the knowledge about the possible variations for the physiotherapists, sports medicine specialists, anthropologists and so on makes the results of the study noteworthy.

\section{KEYWORDS}

Plantaris, Origin, Insertion, Agenesis, Accessory Plantaris.

HOW TO CITE THIS ARTICLE: Jayasree K, Ashalatha PR, Nair SS, et al. Variations of muscle plantaris: anatomical and clinical implications. J. Evolution Med. Dent. Sci. 2016;5(45):2792-2796, DOI: 10.14260/jemds/2016/652

\section{INTRODUCTION}

Plantaris is a small fusiform muscle with a long thin tendon, belonging to the superficial group of flexor muscles of the posterior compartment of leg along with gastrocnemius and soleus. The term plantaris is derived from the Latin word 'planta' meaning the 'sole of foot.' It has been suggested that the plantaris is a vestigial remnant of human's quadrupedal ancestry and was earlier attached to the plantar aponeurosis, but with the evolutionary process of erect posture, the insertion of the muscle got shifted to a higher position. Embryologically, plantaris is considered as a derivative of the

Financial or Other, Competing Interest: None.

Submission 20-04-2016, Peer Review 14-05-2016,

Acceptance 20-05-2016, Published 04-06-2016.

Corresponding Author:

Dr. K. Jayasree,

Professor \& HOD

Department of Anatomy

Government Medical College, Manjeri,

Malappuram-676121, Kerala.

E-mail: jsreek@gmail.com

DOI: $10.14260 /$ jemds $/ 2016 / 652$ deeper portion of the lateral head of gastrocnemius and often represented as the 'third head of gastrocnemius' or 'gastrocnemius tertius' as advocated by McMurrich JP.2 The mode of origin of the muscle and the insertion of its tendon varies considerably. ${ }^{1}$ Also absence of the muscle and rarely the existence of accessory muscle have been studied and reported in the literature by various workers like Ahmed and Sarwari, ${ }^{3}$ Kwinter D.M. 4

\section{MATERIALS AND METHODS}

The study was conducted in 50 lower limbs (right 25, left 25) of properly embalmed cadavers which were utilized for the routine dissection of MBBS students as well as those dissected for mounting as museum specimens in the Department of Anatomy, Govt. Medical College, Manjeri. Of the 50 lower limbs, 44 belonged to adult male and 6 belonged to adult female cadavers. After the dissection of the popliteal fossa, followed by the superficial dissection of the posterior compartment of leg, the plantaris muscle was identified and carefully isolated. The origin, course, insertion and nerve supply of the muscles were meticulously dissected in all the limbs. The related muscles, vessels and nerves were carefully 
preserved. The morphological features of all plantaris muscles in general, the length, breadth and thickness of the muscles and tendons which showed variations in origin and insertion, in particular were noted, documented and photographed. The length of the muscle was measured from its origin to the myotendinous junction and that of the tendon from the myotendinous junction to its distal attachment. Dissecting instruments, thread, measuring tape and digital camera were used for the purpose. The agenesis of the muscle, when noted in 4 limbs was confirmed by careful dissection.

The plantaris muscle with two heads of origin, noted in three limbs, two of which belonged to same male cadaver and the third one in the right limb of another male cadaver, were studied in detail and photographed.

For the evaluation of the pattern of origin and insertion of the muscles, the Types 1-6 (origin) and Types 1-5 (insertion) described in the study of Ahmed and Sarwari, ${ }^{3}$ as given below, was followed.

\section{Origin Patterns}

Type-1: Supra condylar ridge and oblique popliteal ligament. Type-2: Supra condylar ridge, lateral condyle and capsule of knee joint.

Type-3: Supra condylar ridge and lateral condyle of femur. Type-4: Supra condylar ridge, lateral condyle, capsule of knee joint and lateral patellar ligament.

Type-5: Lateral condyle of femur only.

Type-6: Supra condylar ridge and inter digitations with lateral head of gastrocnemius.

\section{Insertion Patterns}

Type-1: On the calcaneum medial to Achilles tendon.

Type-2: Fan shaped expansion superficial to Achilles tendon.

Type-3: Fan shaped expansion deep to Achilles tendon.

Type-4: Fan shaped expansion deep to Achilles tendon and flexor retinaculum.

Type-5: With the Achilles tendon to the calcaneum.

The origin and insertion of all the muscles studied were compared with the above types and categorised.

\section{RESULTS AND ANALYSIS}

Among the 50 lower limbs studied (25 right and 25 left) the plantaris muscle was absent in 4 limbs, 1 right and 3 left, belonging to four different male cadavers.

\section{Pattern of Origin}

In the 3 limbs, 2 right and 1 left, the plantaris was seen to have two distinct heads of origin - accessory plantaris or biceps plantaris - the details of which are considered separately.

Out of the remaining 43 limbs, the origin of plantaris belonged to Type 1 in 10 limbs (23.26\%), Type 2 in 7 limbs (16.28\%), Type 3 in 20 limbs (46.51\%) and Type 5 in 6 limbs (13.95\%) Table 1.

\section{Pattern of Insertion}

Out of the 43 limbs, insertion of plantaris belonged to Type 1 in 17 limbs (39.53\%), Type 3 in 6 limbs (13.95\%) and Type 5 in 20 limbs (46.52\%) Table 2.

\section{Accessory Plantaris}

Out of the 46 plantaris studied, the plantaris in 3 limbs (2 right and 1 left) had two distinct heads of origin. Of the three cases, two belonged to the same adult male cadaver.

\section{Case 1}

Plantaris in the right limb had two heads of origin - upper and lower.

The upper head originated from the lateral supracondylar ridge and oblique popliteal ligament, a little above the origin of lateral head of gastrocnemius (Type 1 origin). It was $5.5 \mathrm{~cm}$ in length, 1.5 in breadth. The lower head was inferomedial to the upper head taking origin from the lower part of the posterior surface of lateral condyle of femur (Type 5 origin). It was $6 \mathrm{~cm}$ in length and $2 \mathrm{~cm}$ in breadth.

Both bellies had separate tendons, which descended and joined together to form a common tendon at the level of the lower border of popliteus muscle (Figure 1). The common tendon had a length of $30 \mathrm{cms}$ from the musculotendinous junction to its distal attachment. The myotendinous portion of the upper head crossed the popliteal artery from the lateral to medial side superficial to the artery and deep to the popliteal vein and tibial nerve. The tendon of the lower head passed from the lateral-to-medial side, superficial-to-popliteal artery and vein and deep to tibial nerve. At the termination, the common tendon showed a fan shaped expansion deep to tendocalcaneus (Achilles tendon) and was inserted to posterior surface of calcaneum, Type 3 insertion.

\section{Case 2}

The right plantaris originated by two fleshy bellies, the upper one from the oblique popliteal ligament and the lower one from the lower part of the posterior surface of the lateral condyle of femur, medial to the origin of the lateral head of gastrocnemius.

Upper belly was $6 \mathrm{cms}$ in length and $2 \mathrm{cms}$ in breadth. Lower belly was $3 \mathrm{~cm}$ in length and $1.5 \mathrm{~cm}$ in breadth. The two bellies merged forming a common tendon of length $31.5 \mathrm{~cm}$, which passed medial-to-tendocalcaneus and at the insertion fanned out deep to it, Type 3 insertion.

\section{Case 3}

The left plantaris originated by two separate fleshy heads, the upper one from the lateral supracondylar line and the lower one from the lower part of lateral condyle of femur.

The upper one was $6 \mathrm{cms}$ in length and $2 \mathrm{cms}$ in breadth. The lower one was $3 \mathrm{cms}$ in length and $1.5 \mathrm{cms}$ in breadth. The two heads merged to form a common belly, which extended for a length of $4 \mathrm{cms}$ before forming a common tendon (Figure 2). The tendon of length $31 \mathrm{~cm}$ passed medial-to-tendocalcaneus and at the insertion fanned out deep to it, Type 3 insertion (Figure 3).

Excluding the three accessory muscles, the other 43 plantaris were having the length varying from $6 \mathrm{cms}$ to $11 \mathrm{cms}$ (mean $9 \mathrm{cms}$ ) and breadth $2.5 \mathrm{cms}$ to $4 \mathrm{cms}$ (mean $3 \mathrm{cms}$ ).

In all the 46 plantaris studied, the nerve supply was derived from the tibial nerve.

Total No. of Specimens: 43 (Excluding those showing agenesis/accessory plantaris). 


\begin{tabular}{|c|c|c|c|c|}
\hline $\begin{array}{c}\text { Type of } \\
\text { Origin }\end{array}$ & Present Study & \multicolumn{2}{|c|}{ Ahmed and Sarwari } \\
\cline { 2 - 5 } Frequency & Percentage & Frequency & Percentage \\
\hline Type 2 & 10 & 23.26 & 12 & 25.00 \\
\hline Type 3 & 20 & 46.51 & 17 & 35.41 \\
\hline Type 4 & 0 & 0 & 2 & 4.16 \\
\hline Type 5 & 6 & 13.95 & 2 & 4.16 \\
\hline Type 6 & 0 & 0 & 1 & 2.08 \\
\hline Total & $\mathbf{4 3}$ & $\mathbf{1 0 0}$ & $\mathbf{4 8}$ & $\mathbf{1 0 0}$ \\
\hline Table 1: Showing the Percentage and Frequencies of \\
Different Types of Origin, In Comparison with \\
The Study of Ahmed and Sarwari \\
\hline
\end{tabular}

Total No. of Specimens: 43

\begin{tabular}{|c|c|c|c|c|}
\hline $\begin{array}{c}\text { Type of } \\
\text { Inserti } \\
\text { on }\end{array}$ & $\begin{array}{c}\text { Prequen } \\
\text { cy }\end{array}$ & $\begin{array}{c}\text { Percenta } \\
\text { ge }\end{array}$ & $\begin{array}{c}\text { Frequen } \\
\text { cy }\end{array}$ & $\begin{array}{c}\text { Percenta } \\
\text { ge }\end{array}$ \\
\cline { 2 - 5 } Type 1 & 17 & 39.54 & 33 & 68.75 \\
\hline Type 2 & 0 & 0 & 5 & 10.41 \\
\hline Type 3 & 6 & 13.95 & 2 & 4.16 \\
\hline Type 4 & 0 & 0 & 2 & 4.16 \\
\hline Type 5 & 20 & 46.51 & 6 & 12.50 \\
\hline Total & 43 & 100 & 48 & 100 \\
\hline Table 2: Showing the Percentage and Frequencies of \\
Different Types of Insertion, In Comparison \\
with The Study of Ahmed and Sarwari \\
\hline
\end{tabular}

\begin{tabular}{|c|c|c|c|c|c|}
\hline $\begin{array}{l}\text { Present } \\
\text { Study }\end{array}$ & Standring & \begin{tabular}{|l|} 
Ahmed \\
and \\
Sarwari
\end{tabular} & $\begin{array}{c}\text { Simpson } \\
\text { et al }\end{array}$ & $\begin{array}{l}\text { Mohini M } \\
\text { Joshi et al }\end{array}$ & $\begin{array}{l}\text { Daseler } \\
\text { and } \\
\text { Anson }\end{array}$ \\
\hline $8 \%$ & $10 \%$ & $4 \%$ & $7-20 \%$ & $\begin{array}{c}\text { Rt.limb- } \\
6.66 \% \\
\text { Lt.limb- } \\
12.82 \%\end{array}$ & $\begin{array}{c}\text { Male- } \\
8.2 \% \\
\text { Female- } \\
5.8 \%\end{array}$ \\
\hline \multicolumn{6}{|c|}{$\begin{array}{l}\text { Table 3: \% of Absence of Plantaris } \\
\text { In Comparison with Other Studies }\end{array}$} \\
\hline
\end{tabular}

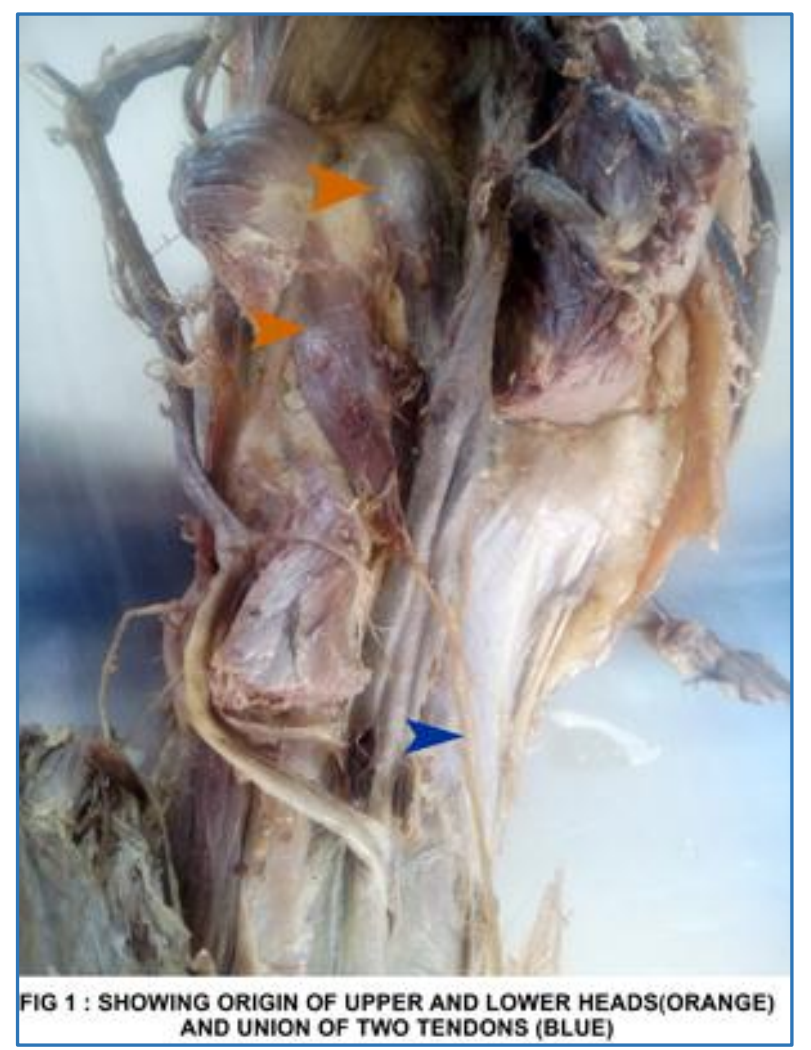

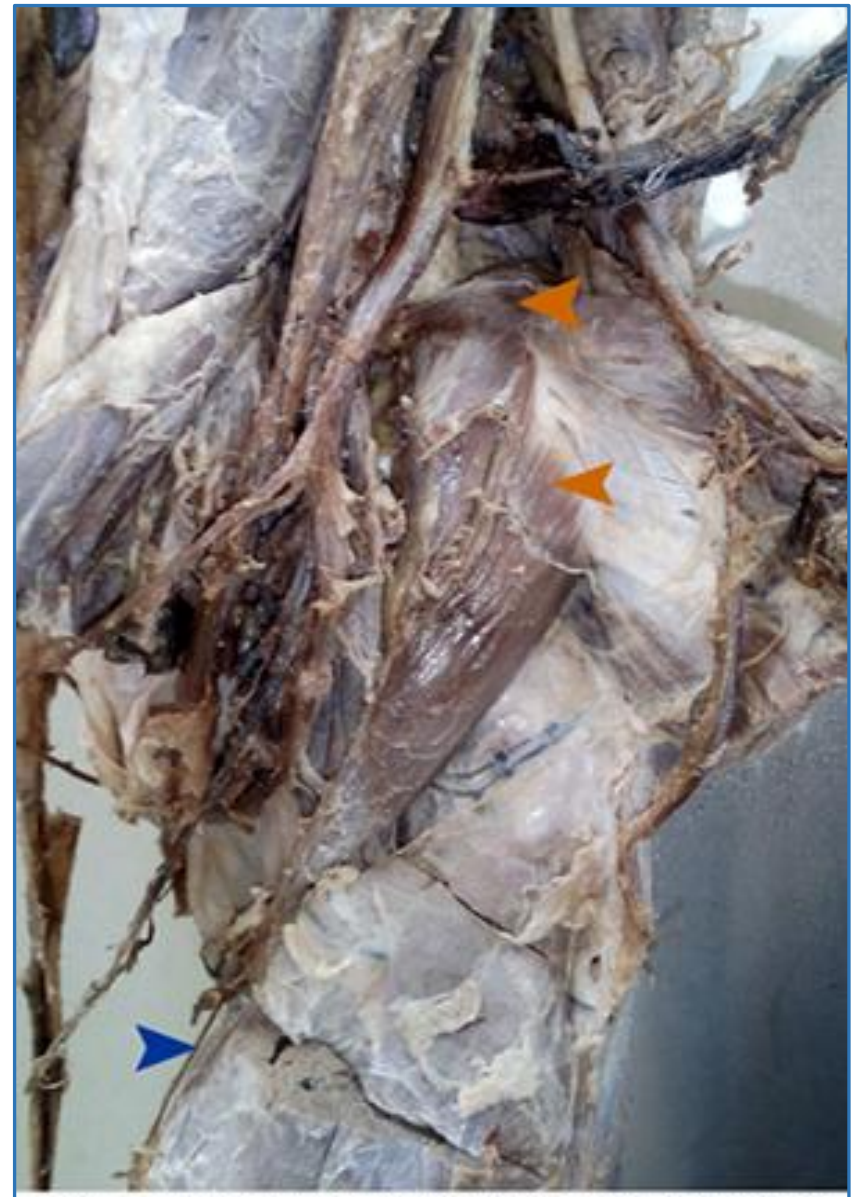

FIG 2 : SHOWING UPPER AND LOWER HEADS MERGING TO FORM A COMMON BELLYY WITH A COMMON TENDON

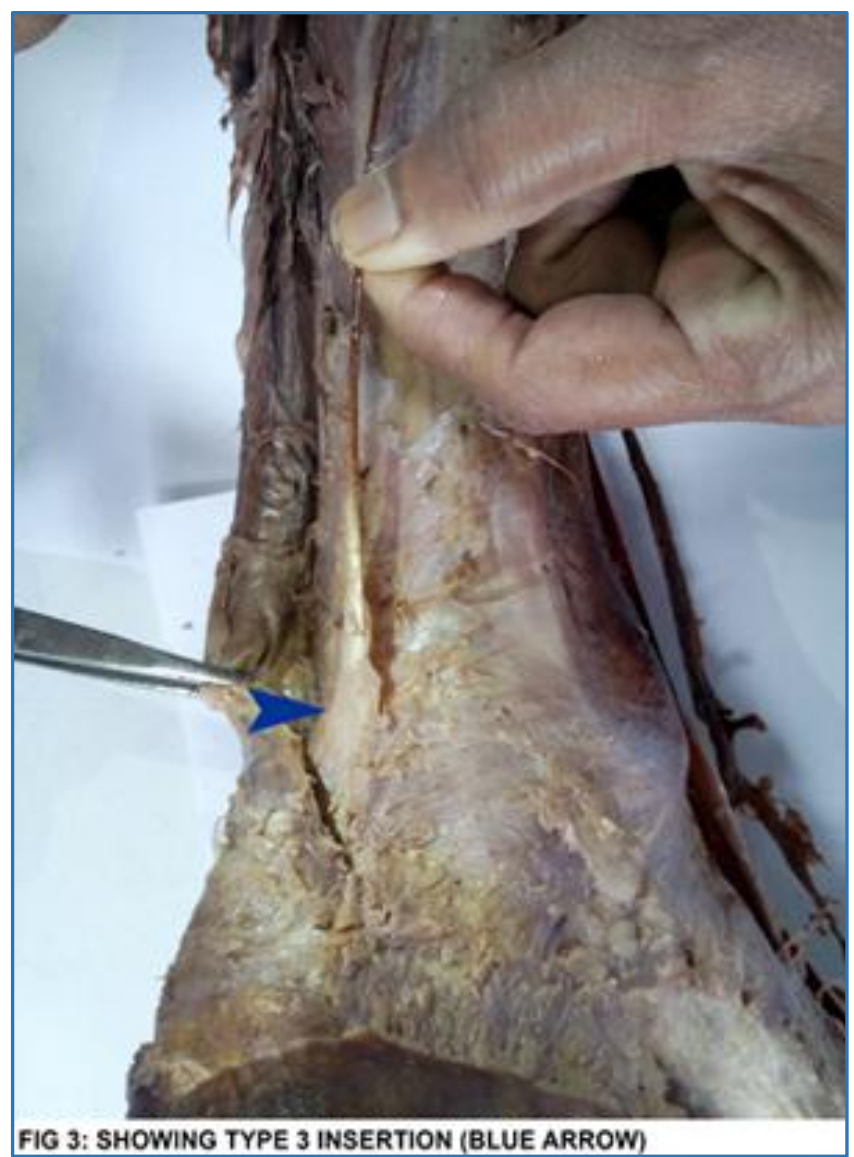




\section{DISCUSSION}

Plantaris muscle is known to exhibit many anatomical variations in terms of its occurrence, origin, relation with the neighbouring neurovascular structures and insertion. Absence of the muscle and rarely accessory plantaris have also been reported in the literature. In the present study of plantaris muscle in 50 lower limbs, variations have been observed in the pattern of origin and insertion. Agenesis of the muscle as well as accessory plantaris have also been identified in the study.

Normally, plantaris originates from the inferior part of the lateral supracondylar line of femur and oblique popliteal ligament. ${ }^{5}$ In the present study $23.26 \%$ of plantaris had this pattern of origin.

Reports are available in the literature regarding the anomalous sites of origin of this muscle which includes, 1) The lower part of the linea aspera, 2) The posterior ligament of the knee at the intercondylar space, 3) Fascial covering of popliteus, 4) The fibula between flexor hallucis longus and peroneus longus, 5) Oblique line of tibia under the cover of soleus, 6) Lateral condyle of femur above the origin of lateral head of gastrocnemius. ${ }^{1}$ In the present study such anomalous origin of plantaris were not found.

In the present study, the origin patterns of the muscle as evaluated following the types described by Ahmed and Sarwari, 3 Types 4 and 6 were not shown by any muscle.

Normally, the myotendinous junction of plantaris occurs approximately at the level of origin of soleus muscle from tibia in the proximal part of leg, the long tendon passes between the medial head of gastrocnemius and soleus, continues along the medial aspect of tendocalcaneus for its insertion on calcaneum either independently or in association with tendocalcaneum, Andreo A Spina DC. 6

The mode of insertion of plantaris tendon frequently varies and it may take either of the following: a) Soft tissue between gastrocnemius and soleus, b) Medial border of calcaneal tendon at its insertion, d) Bursa between the calcaneal tendon and calcaneus, e) Fibrofatty tissue of the calcaneal tendon, f) Plantar aponeurosis, Daseler. ${ }^{1}$

In the present study, according to the types described by Ahmed and Sarwari, ${ }^{3}$ 39.53\% had Type 1 insertion, 13.95\% Type 3 insertion and $46.52 \%$ Type 5 insertion. In no case, Types 2 and 4 were seen.

In the present study, plantaris was absent in 4 cases (8\%). Unilateral or bilateral absence of plantaris has been reported by various workers. When absent, it is likely that the separation of the muscle from the lateral head of gastrocnemius has failed to take place. The agenesis of plantaris was noted bilaterally in a male cadaver 1 . In the case report of variant insertion of plantaris by Sugavasi. ${ }^{7}$ the tendon of plantaris was found absent as the muscle belly ended in the form of a thin fascia through which it fused with soleus muscle. The muscle may be absent in $10 \%$ of human population according to Standring S. ${ }^{5}$ In the sonographic investigations, plantaris was found absent in 7-20\% of limbs, Simpson. ${ }^{8}$ In the study of Mohini M Joshy. ${ }^{9}$ regarding the morphological variations of plantaris, an absence of muscle was reported to be $6.66 \%$ in Rt. Limb and $12.82 \%$ in Lt. Limb. The plantaris was found absent in $8.2 \%$ male limbs and $5.8 \%$ female limbs, Daseler. ${ }^{1}$ Table 3.

Bilateral absence is common than unilateral absence; unilateral absence is found to be frequent on left side, Kwinter. 4
Considering the three limbs with accessory plantaris, each one had two distinct heads of origin. In the first case, the origin of upper head was corresponding to type 1 and that of lower head type 5 . The common tendon had type 3 insertion. The unusual relation of the tendons of the two bellies encircling the popliteal vein (One tendon deep and the other superficial to the vein) before becoming a single tendon as in the case was never seen while reviewing the available literature. Contraction of the two bellies of plantaris along with gastrocnemius and soleus may compress the vein and can cause venous stasis and associated complications. The second accessory plantaris had the upper belly originated from oblique popliteal ligament alone (Not corresponding to any of the above types) and lower one corresponding to type 5 . Insertion pattern was type 3. In the third case, the upper belly originated from the lateral supracondylar ridge alone (Not corresponding to any of the above type) and the lower one corresponding to type 5 . The two bellies merged to form a common belly and became a biceps plantaris, similar to the finding in the study of Sachin Soni. ${ }^{10}$ Insertion pattern was type 3.

In the case report of Phalguni Srimani. ${ }^{11}$ a variant origin of plantaris with two distinct heads, a lateral and medial which soon join together to form a common tendon inserted into flexor retinaculum of ankle is described.

Sharadkumar. ${ }^{12}$ reported a case of a plantaris with two heads of origin, one from lateral supracondylar line and the other from oblique popliteal ligament, united to form a common tendon which was inserted separately into the medial side of calcaneum.

In a retrospective review of 1000 consecutive MRI studies of the knee, an accessory plantaris muscle was detected in 63 cases (6.3\%), 38 males and 25 females. ${ }^{13}$ These plantaris had abnormal insertions to iliotibial tract and lateral patellar retinaculum.

Bilateral double plantaris muscle in a 45 -year-old male has been reported by Rana. ${ }^{14}$ Sherry Sharma. ${ }^{15}$ has reported a unilateral accessory plantaris, which showed complete duplication, i.e. two separate bellies of origin and two separate tendons of insertion. Such cases were not found in the present study.

\section{CONCLUSION}

Despite of its vestigial nature, documentation of the anatomical variations of plantaris is clinically relevant. The anatomical knowledge of the muscle is important for the clinical diagnosis of "tennis leg" resulting from the rupture of plantaris. The plantaris muscle has been used as an excellent graft, Simpson. ${ }^{8}$ Plantaris tendon graft for reconstruction of anterior tibiofibular and calcaneofibular ligament has been described in the studies of Pagenstert GI.16 Injury of plantaris is one of the causes of unexplained painful calf. Clinically, plantaris muscle is primarily of concern in the differential diagnosis of lower extremity pain as its rupture is indistinguishable from deep vein thrombosis without the assistance of high resolution ultrasound or MRI, Lopez. ${ }^{17}$ The tendon of plantaris muscle having extremely tensile strength has been used successfully for flexor tendon replacement in hand and even for atrioventricular valve repair, Shuhaiber. ${ }^{18}$ Plantaris has been considered to be an organ of proprioceptive function for the larger, more powerful plantar flexors as it contains a high density of muscle spindles, Bardeen CR.19 
Plantaris is a weak flexor of knee and ankle. Removal of plantaris muscle does not cause any dysfunction of lower limb in presence of other flexors like gastrocnemius and soleus. Yet, considering the various clinical relevance of the muscle, its presence and possible anatomical variations cannot be undermined.

The presence of accessory plantaris in the present study may be of academic interest as the standard textbooks in Anatomy mentions very little about this fact.

\section{REFERENCES}

1. Daseler EH, Anson BJ. The plantaris muscle. J Bone Joint Surgery 1943;25(4):822-7.

2. McMurrich JP. The phylogeny of the crural flexors. Am J Anat 1905;4:33-48.

3. Ahmed N, Sarwari KN. Morphological variations and surgical importance of the plantaris muscle in humans. Indian Journal of fundamental and applied life sciences 2013;3(4):342-6.

4. Kwinter DM, Lagrew JP, Kretzer J, et al. Unilateral double plantaris muscle: a rare anatomical variation. International Journal of Morphology 2010;28(4):1097-9.

5. Standring S. Gray's anatomy. The anatomical basis of clinical practice, $40^{\text {th }}$ edn. Philaldelphia: Elsevier Churchill Livingstone 2008; 1421.

6. Andreo A, Spina DC. The plantaris muscle: anatomy, injury, imaging and treatment. J Can Chiropr Assoc 2007;51(3):158-65.

7. Sugavasi R, Latha K, Indira Devi J, et al. A case report of variant insertion of plantaris muscle and its morphological and clinical implications. J Morphol Sci 2013;30(4):304-5.

8. Simpson SL, Hertzog MS, Barja RH. The plantaris tendon graft: an ultrasound study. Journal of Hand surgery American 1991;16(4):708-11.

9. Mohini M Joshi, Subhash D Joshi, Sharda S Joshi. Morphological variations of muscle plantaris, anatomical and clinical insight. International journal of Anatomy and Research Int J Anat Res 2014;2(4):621-4.
10. Sachin Soni, Alok Saxena, Tuhin Ghulyani, et al. A biceps plantaris in the popliteal region, a case report. Eur J Anat 2014;18(1):32-3.

11. Phalguni Srimani, Rudradev Meyur, Alpana De (Bose), et al. Unilateral variation of plantaris muscle, a case report. Journal of Evolution of medical and dental sciences 2014;3(3):618-22.

12. Sharadkumar PS, Shaguphta TS, Rakhi MM. A rare variation of plantaris muscle. International journal of biological and medical research 2012;3(4):2437-40.

13. Herzog RJ. Accessory plantaris muscle, anatomy and prevalence. HSSJ 2011;7(1):52-6.

14. Rana K, Das S, Verma R. Double plantaris muscle, a cadaveric study with clinical importance. Int J Morphol 2006;24(3):495-8.

15. Sherry Sharma, Meenakshi Khullar, Sunil Bhardwaj. Unilateral accessory plantaris muscle, a rare anatomical variation with clinical implications. Global Journal of medical research 2014;9(4):39-42.

16. Pagenstert GI, Valderrabano V, Hintermann B. Lateral ankle ligament reconstruction and free plantaris tendon graft. Techniques in foot \& ankle surgery 2005;4(2):10412.

17. Lopez GJ, Hoffman RS, Davenport M. Plantaris rupture, a mimic of deep vein thrombosis. J Emerg Med 2009;30(2):344-8.

18. Shuhaiber JH, Shuhaiber HH. Plantaris tendon graft for atrioventricular valve repair, a novel hypothetical technique. Texas heart institute journal 2003;30(1):42-4.

19. Bardeen CR. Development and variation of the nerves and the musculature of the inferior extremity and of the neighbouring regions of the trunk in man. Am J Anat 1906;6(1):259-390. 